\title{
Adolescents' Perceptions of Social Status: Development and Evaluation of a New Indicator
}

\section{Citation}

Goodman, E., N. E. Adler, I. Kawachi, A. L. Frazier, B. Huang, and G. A. Colditz. 2001.

"Adolescents' Perceptions of Social Status: Development and Evaluation of a New Indicator." PEDIATRICS 108 (2): e31-e31. https://doi.org/10.1542/peds.108.2.e31.

\section{Permanent link}

http://nrs.harvard.edu/urn-3:HUL.InstRepos:41288280

\section{Terms of Use}

This article was downloaded from Harvard University's DASH repository, WARNING: This file should NOT have been available for downloading from Harvard University's DASH repository.

\section{Share Your Story}

The Harvard community has made this article openly available.

Please share how this access benefits you. Submit a story.

\section{Accessibility}




\title{
Adolescents' Perceptions of Social Status: Development and Evaluation of a New Indicator
}

\author{
Elizabeth Goodman, MD*¥; Nancy E. Adler, PhD§; Ichiro Kawachi, MD, PhD\|I; A. Lindsay Frazier, MD\|\#; \\ Bin Huang, MS*; and Graham A. Colditz, MD, DrPH\|
}

\begin{abstract}
Objective. Eliminating health disparities, including those that are a result of socioeconomic status (SES), is one of the overarching goals of Healthy People 2010. This article reports on the development of a new, adolescent-specific measure of subjective social status (SSS) and on initial exploratory analyses of the relationship of SSS to adolescents' physical and psychological health.
\end{abstract}

Methods. A cross-sectional study of 10843 adolescents and a subsample of 166 paired adolescent/mother dyads who participated in the Growing Up Today Study was conducted. The newly developed MacArthur Scale of Subjective Social Status (10-point scale) was used to measure SSS. Paternal education was the measure of SES. Indicators of psychological and physical health included depressive symptoms and obesity, respectively. Linear regression analyses determined the association of SSS to depressive symptoms, and logistic regression determined the association of SSS to overweight and obesity, controlling for sociodemographic factors and SES.

Results. Mean society ladder ranking, a subjective measure of SES, was $7.2 \pm 1.3$. Mean community ladder ranking, a measure of perceived placement in the school community, was $7.6 \pm 1.7$. Reliability of the instrument was excellent: the intraclass correlation coefficient was 0.73 for the society ladder and 0.79 for the community ladder. Adolescents had higher society ladder rankings than their mothers $\left(\mu_{\text {teen }}=7.2 \pm 1.3 \mathrm{vs} \mu_{\text {mom }}=6.8 \pm 1.2\right.$; $P=.002)$. Older adolescents' perceptions of familial placement in society were more closely correlated with maternal subjective perceptions of placement than those of younger adolescents (Spearman's rho teens $<15$ years $=$ 0.31 vs Spearman's rho teens $_{215}$ years $=0.45 ; P<.001$ for both). SSS explained $9.9 \%$ of the variance in depressive symptoms and was independently associated with obesity (odds ratio society $=0.89,95 \%$ confidence interval $=$ $0.83,0.95$; odds ratio community $=0.91,95 \%$ confidence interval $=0.87,0.97$ ). For both depressive symptoms and obesity, community ladder rankings were more strongly associated with health than were society ladder rankings in models that controlled for both domains of SSS.

From the *Children's Hospital Medical Center and $\ddagger$ Department of Pediatrics, University of Cincinnati College of Medicine, Cincinnati, Ohio; §Department of Psychiatry, University of California, San Francisco, California; \|Channing Laboratory, Department of Medicine, Brigham and Women's Hospital, and Harvard Medical School, and IDDepartment of Health and Social Behavior, Harvard School of Public Health, Boston, Massachusetts; and \#Department of Pediatric Oncology, Dana Farber Cancer Institute, Boston, Massachusetts.

Received for publication Dec 19, 2000; accepted Apr 3, 2001.

Reprint requests to (E.G.) Division of Adolescent Medicine, Children's Hospital Medical Center, 3333 Burnet Ave, Cincinnati, OH 45229. E-mail: goodeØ@chmcc.org

PEDIATRICS (ISSN 0031 4005). Copyright (C) 2001 by the American Academy of Pediatrics.
Conclusions. This new instrument can reliably measure SSS among adolescents. Social stratification as reflected by SSS is associated with adolescents' health. The findings suggest that as adolescents mature, SSS may undergo a developmental shift. Determining how these changes in SSS relate to health and how SSS functions prospectively with regard to health outcomes requires additional research. Pediatrics 2001;108(2). URL: http:// www.pediatrics.org/cgi/content/full/108/2/e31; subjective social status, socioeconomic status, obesity, depression, adolescence.

ABBREVIATIONS. SSS, subjective social status; SES, socioeconomic status; BMI, body mass index; GUTS, Growing Up Today Study; NHSII, Nurses' Health Study II.

$\mathrm{T}$ The elimination of health disparities among different population segments, including differences related to socioeconomic status (SES), is the second overarching goal of Healthy People 2010. Recently, the American Academy of Pediatrics also recognized and highlighted the importance of addressing SES as an causative agent in the creation of health differentials and called for additional research to understand the impact of SES across the life course. ${ }^{1}$

The inverse, graded relationship between SES and infant, child, and adult health is well established. . $^{2-11}$ However, among adolescents, the SES gradient in health is present inconsistently. ${ }^{12-15} \mathrm{~A}$ number of models have been proposed to explain the different patterning of SES effects on adolescent health.2,16 Choosing the most appropriate model(s) has been hampered by 2 major barriers. First is the lack of understanding of the mechanisms underlying the SES-health relationship, in general. Second, there is a lack of youth-specific indicators of social status. A new, youth-specific measure of subjective perceptions of social status-the MacArthur Scale of Subjective Social Status-Youth Version-allows us to address both of these barriers and assess the effects of social status among adolescents using a broader conceptualization of this construct. This article describes the development and initial testing of the MacArthur Scale of Subjective Social Status-Youth Version and discusses implications for future research on unraveling the mechanisms behind socioeconomic disparities in health. 


\section{RATIONALE FOR INSTRUMENT DEVELOPMENT}

Although income, education, and occupation (the traditional variables used to measure SES) are only moderately correlated with each other, all are associated with health in a similar manner. This suggests that all 3 individually reflect an underlying common component of social status. ${ }^{17,18}$ Although the SES gradient in health has been studied widely, how social status causes poorer health is not clear. This may be, in part, because social status has been defined as SES, which is an external, purely objective measure that does not account for subjective, internalized perceptions of social status. Wilkinson ${ }^{19,20}$ argued that these subjective perceptions of relative ranking may be more important determinants of health than objective indicators, such as income, which assess material resources. ${ }^{21}$

Despite the vast literature on SES's effects on health, little is known about people's perceptions of their placement in the social hierarchy, what determines these perceptions, or how these perceptions relate to health. This is true for both adults and adolescents. Research has been hampered by a lack of indicators of subjective social status. Studies have relied, instead, on measures of social class identification and have focused on political and cultural attitudes and behavior. ${ }^{22-30}$ Almost none have looked at health. Two major problems exist with the use of class identification as a proxy for social status. The categorical nature of the measures of social class identification does not adequately tap the full spectrum of socioeconomic stratification. In addition, socially charged language is used to describe the discrete classes. Social desirability may be figuring prominently in an individual's choice of middle versus upper class, working versus lower class. The MacArthur Scale of Subjective Social Status was developed to address these problems and assess perceived placement within the social hierarchy among adults by using a visual scale. ${ }^{18}$ The instrument is a drawing of a ladder on which people place themselves. The instrument has 2 parts, 1 linked to traditional SES indicators (a ladder assessing placement in society) and 1 linked to standing in a more local, immediate social environment (a ladder assessing placement in community). These ladders have been used in several studies among adults, and results suggest that ladder rankings are more powerful determinants of health-related outcomes than traditional measures of SES. 18,31,32 Whether similar associations might be shown at different stages in the life course, including adolescence, has not been tested.

Adolescence is a critical developmental period to study with regard to social stratification and the sociobiologic translation. During adolescence, the transition between social status of childhood, which is determined primarily by familial social status, and adult social status, which is more self-determined, occurs and an individual's perceptions of social stratification crystallize. Health indicators of infants and young children, such as infant mortality and immunization status, used in studies of social determinants of infant and child health, reflect parent-based social inequalities in health and, often, parental beliefs and behaviors, as well. As an adolescent's selfconceptualization matures, perceptions of social status may be based on both parental SES and the adolescent's sense of his or her own standing. In addition, beliefs, behaviors, and physiologic changes that develop in adolescence have great potential to have an impact on health. Thus, it is likely that differences between family (parent-based) measures and self (adolescent-specific) measures would develop during the teenage years. The lack of a consistent graded effect of SES on adolescent health may be because most analyses that assess the SES-health gradient among adolescents use parental measures of SES, which do not tap the adolescent's emerging self-concept of social stratification. ${ }^{33}$

\section{MacARTHUR SCALE OF SUBJECTIVE SOCIAL STATUS-YOUTH VERSION}

To address the need for a youth-specific indicator of subjective social status, we modified the MacArthur Scale of Subjective Social Status to be applicable to adolescents. We did this because use of the adult scale, which asks the individual to place him- or herself relative to others in American society with regard to education, income, and occupation, is not appropriate for adolescents, the vast majority of whom are still in school, are not financially independent, and are not employed full time.

Like its adult counterpart, this instrument has 2 ladders (Fig 1). The first ladder assesses familial placement in US society and is meant to parallel the adult ladder assessing personal placement within society. This ladder is a measure of subjective SES. Comparisons between adolescent and adult responses to this ladder are meaningful as both the adult and adolescent society ladders anchor the ladder to the same reference group: US society. The second ladder assesses personal placement in the school community. It has been suggested that social status among peers is of equal or greater importance to the SES-health relationship among adolescents as parental social status. Glendinning et $\mathrm{al}^{34}$ found that the pattern of social integration was associated with health behaviors such as smoking and drinking independent of social class background. Given the rise in meaning of peers to an adolescent's self-concept as they mature, it is important to explore the relationship between social status in a community of peers. The school community ladder fulfills this need for in-school youths. Because this ladder specifies the school community as the reference group, the youth version of this ladder is not consistent with the adult instrument, which asks individuals to define community "however it is meaningful to you." Some adults use their neighborhood as the reference, others use their work, and still others use friends. Therefore, comparisons between adult and youth responses to the community ladder should be interpreted with this difference in mind. The youth version of the MacArthur Scale is easy to comprehend and is appropriate for those in grade 7 and higher, approximately age 12 and older. 
1a. Imagine that this ladder pictures

how American society is set up.

- At the top of the ladder are the people who are the best off--they have the most money, the highest amount of schooling, and the jobs that bring the most respect.

- At the bottom are people who are the worst off--they have the least money, little or no education, no job or jobs that no one wants or respects.

Now think about your family. Please tell us where you think your family would be on this ladder. Fill in the circle that best represents where your family would be on this ladder.

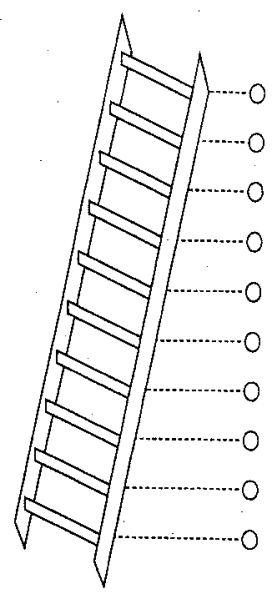

Fig 1. The MacArthur Scale of Subjective Social Status-Youth Version.

1b. Now assume that the ladder is a way of picturing your school.
- At the top of the ladider are the people in your school with the most respect, the highest grades, and the highest standing.
- At the bottom are the people who no one respects, no one wants to hang around with, and have the worst grades.
Where would you place yourself on this ladder? Fill in the circle that best represents where you would be on this ladder.

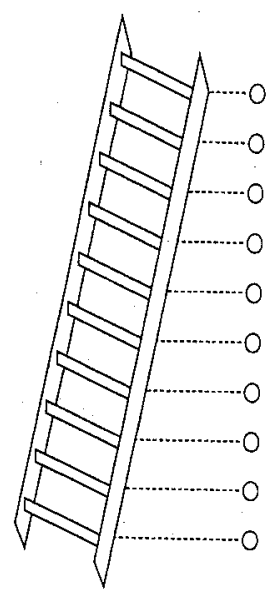

\section{INITIAL HYPOTHESES RELATING SUBJECTIVE AND OBJECTIVE SOCIAL STATUS TO ADOLESCENT HEALTH}

On the basis of the literature regarding social class identification, social stratification, and the SES gradient in health, we developed 3 initial hypotheses about the relationships between objective and subjective social status and health among adolescents. First, we hypothesized that adolescents' perceptions of family standing within society will be higher than maternal perceptions of social status within society. Second, we hypothesized that as adolescents age, there will be less upward bias in their perceptions of social status. Therefore, older adolescents will have lower perceptions of social status with regard to familial placement in society than younger adolescents, and concordance between adolescent and maternal scores on the society ladder will be greater among older than among younger adolescents. These 2 hypotheses are based on the earlier work of Centers, ${ }^{29}$ which showed that adolescents' perceptions of stratification tend to be more optimistic than those of adults and that this tendency toward upward identification lessened with increasing age. Last, we hypothesized that SSS, especially the school community ladder, will be associated with indicators of adolescent's physical and mental health indepen- dent of the effects of traditional, family-based measures of SES. This hypothesis represents an early assessment of the relationship of perceptions of social status to health outcomes and of whether subjective assessments of stratification are more powerful predictors of health than objective measures of SES. To test this hypothesis, we identified 2 specific health outcomes that represent significant morbidities among adolescents, have been associated with SES, and were assessed in the cohort that we studied (see below) as our health indicators. ${ }^{12}$ These included depressive symptoms and obesity. Depression is a serious morbidity among adolescents and carries with multiple sequelae, including poor school performance, lower self-esteem, suicidal tendencies, and substance use. ${ }^{35}$ Large epidemiologic studies, such as the Growing Up Today Study (GUTS), assess depressive symptoms rather than perform diagnostic interviewing. Obesity is an increasing, important public health problem throughout the life course and carries multiple medical and psychologic sequelae. ${ }^{36-38}$ More than half of the adult US population older than 19 years is overweight or obese. ${ }^{39}$ Twelve percent of adolescents are obese, defined as having a body mass index (BMI) $>95 \%$ for age and gender. ${ }^{40}$ Overweight adolescents with a BMI between the $85 \%$ and $95 \%$ are considered at risk for 
obesity, and obesity during adolescence is an extremely powerful predictor of obesity during adulthood. ${ }^{41,42}$ Data from multiple national surveillance studies documented a significant increase in the prevalence of overweight and obesity in the past decade. ${ }^{39,43-45}$

\section{METHODS}

\section{Study Samples}

Evaluation of reliability of the MacArthur Scale of Subjective Social Status-Youth Version and testing of these initial hypotheses were performed using 2 large, established cohort studies: GUTS and the Nurses' Health Study II (NHSII). GUTS, which was initiated in 1996, involves more than 16000 children of mothers who are participating in the ongoing NHSII, a prospective cohort study involving 116671 female registered nurses aged 25 to 42 at the initiation of the study in 1989. Details of both the NHSII and GUTS have been reported elsewhere. ${ }^{46,47}$ The MacArthur Scale of Subjective Social Status-Youth Version was added to GUTS in 1999. That year, a total of 10843 participants returned the long form of the survey, which contained the MacArthur Scale of Subjective Social Status-Youth Version;; $58.9 \%$ were female $(n=6382)$, and $54.9 \%(n=5840)$ were younger than 15 years. Mean age was $14.4 \pm 1.6$ years. The cohort was primarily white $(93.3 \%)$, which reflects the demographics of the nursing population.

In addition to the entire 1999 GUTS cohort, 2 subsamples were derived to evaluate the instrument and to test the hypotheses: an adolescent subsample and a mother subsample. The adolescent subsample was used to assess test-retest reliability. A random sample of 184 adolescent who responded to the 1999 survey were sent the MacArthur Scale of Subjective Social Status-Youth Version approximately 2 months after the 1999 survey was distributed; 115 returned the instrument $(62.5 \%$ response rate). There were no significant differences in age or gender among those who responded to the retest and those who did not.

Maternal responses to the adult version of the MacArthur Scale of Subjective Social Status were needed to address the first and second hypotheses. In addition, we wanted to explore how well the only measure of SES in the NHSII, partner education, assessed SES in GUTS. To accomplish these tasks, we mailed to a random sample of mothers of 194 of the 1999 participants a questionnaire that included the MacArthur Scale of Subjective Social StatusAdult Version and questions assessing 1998 household income, maternal education, and nursing degree. Because surveys were mailed and returned within a few-month period, making 1999 income variable depending on when the survey was completed, 1998 household income was assessed; 166 of the 194 mothers returned these surveys, for a response rate of $85.6 \%$. There were no significant differences in age, gender, partner education, MacArthur Scale of Subjective Social Status-Youth Version ladder rankings, or health indicators for the 166 adolescents whose mothers responded compared with the overall 1999 GUTS population. Responses from the 166 mothers were paired with their child's response to the 1999 survey to test hypotheses.

\section{Variables Used in Analyses}

\section{Adolescents' SSS}

The MacArthur Scale of Subjective Social Status-Youth Version was used to assess SSS among adolescents (Fig 1). This newly derived instrument had excellent 2-month test-retest reliability among the subsample of 1151999 GUTS respondents (Table 1). In general, reliability of the community ladder was higher than that of the society ladder. This suggests that adolescents are more consistent in placing themselves within their more immediate social environment than they are at placing their families within the broader social context.

\section{Adults' SSS}

The adult version of the MacArthur Scale of Subjective Social Status was used in the mothers' subsample to assess SSS. ${ }^{18}$ This instrument assesses current subjective perceptions of social status.

\section{SES}

Because these analyses place the adolescent in the context of his or her current environment, sociodemographic factors of the res-
TABLE 1. Two-Month Test-Retest Reliability of MacArthur Scale of Subjective Social Status-Youth Version Among a Subsample of the Growing Up Today Study

\begin{tabular}{lccc}
\hline Parameter & $n$ & $\begin{array}{c}\text { Society } \\
\text { Ladder } \\
\text { Intraclass } \\
\text { Correlation }\end{array}$ & $\begin{array}{c}\text { Community } \\
\text { Ladder } \\
\text { Intraclass } \\
\text { Correlation }\end{array}$ \\
\hline Total & 115 & 0.73 & 0.79 \\
Male & 52 & 0.75 & 0.84 \\
Female & 63 & 0.71 & 0.73 \\
Age $<15$ & 71 & 0.68 & 0.78 \\
Age $\geq 15$ & 44 & 0.83 & 0.81 \\
\hline
\end{tabular}

ident, although not necessarily biological parent(s) or parental figures, are considered here. As mentioned above, no direct individual- level indicators of SES were obtained in GUTS. Mothers of GUTS participants are surveyed every 2 years because they are participants in the NHSII. In 1999, the NHSII asked participants to report current partner or spouse's education, hereafter referred to as "father's education." Current partners and spouses of the NHSII participants are not surveyed directly by either the NHSII or the GUTS. By merging NHSII and GUTS data on a common maternal identifier, we determined that father's education was missing for only $8.8 \%(n=953)$ of the 1999 GUTS respondents. Half of those for whom father's education was missing lived in single-parent families. There was no difference in community ladder rankings among GUTS participants whose mothers did not report father's education compared with those whose mothers did report father's education. However, adolescents whose mothers reported father's education had higher society ladder rankings than those who did not $(P<.001)$. Consistent with the design of GUTS, mothers' report of father's education showed that GUTS is a socioeconomically advantaged cohort: $32.3 \%$ of partners had graduate training, $29.8 \%$ had a 4 -year college degree, $16.8 \%$ had attended a 2 -year college, $16.1 \%$ had a high school degree, and $0.5 \%$ had less than a high school education.

To determine whether father's education adequately assessed SES in the 1999 GUTS cohort, we asked the mother subsample ( $n=166$ ) to report household income in 1998, maternal education, and maternal nursing degree. Father's education was correlated with maternal education (Spearman's rho $=0.22 ; P=.005$ ), nursing degree (Spearman's rho $=0.23 ; P=.005$ ), and household income (Spearman's rho $=0.26 ; P<.001$ ) to the same degree and, therefore, seemed to assess SES adequately. Thus, father's education, which was present for almost the entire GUTS cohort, was used as the indicator of SES in this study. We used the mean of the mother's education among those in the mother's subsample who lived in a single-parent household as the value of father's education for GUTS participants who lived in families with a single mother as the parent.

\section{Health Indicators}

\section{Depressive Symptoms}

GUTS contains 6 Likert-type scale items that assess depressive symptoms, such as feeling worthless or depressed, which were based on the McKnight Risk Factor Survey. ${ }^{48}$ These were summed to create a scale that could range from 6 to 30. Higher scores indicate fewer depressive symptoms. The scale had good reliability (Cronbach's $\alpha=0.73$ ). Mean in the 1999 GUTS cohort was $22.8 \pm 3.5$.

\section{Obesity}

GUTS participants self-reported height and weight. BMI (kg/ $\mathrm{m}^{2}$ ) was calculated from these self-reported measures. BMI from self-report of height and weight has been shown to be a valid method of determining obesity among adolescents. ${ }^{49}$ Overweight was defined as $\mathrm{BMI} \geq 85 \%$ for age and gender and obesity as BMI $\geq 95 \%$ for age and gender. ${ }^{41,50}$ The prevalence of overweight in this cohort was $20.3 \%$ and of obesity was $6.1 \%$.

\section{Covariates}

Sociodemographic covariates used in multivariate analyses included age, gender, race (white vs nonwhite), and number of 
parents in the home. In addition, the relationships between social status and 2 psychological covariates that may have an impact on adolescents' self-perception were assessed. These included selfesteem and popularity. Self-esteem and popularity were assessed by a modified version of the Harter Self-Perception Profile for Children. ${ }^{51}$ This instrument has been included in the GUTS survey yearly since the cohort's inception. The modifications of the Harter scale were based on extensive pilot testing among students in public schools in Salem, Massachusetts. The scale contains a 6 -item assessment of global self-worth (Cronbach's $\alpha=0.85$ ) and a 6-item assessment of social acceptance, a measure of popularity (Cronbach's $\alpha=0.77$ ).

\section{Data Analyses}

Statistical analyses were performed using SAS (SAS Institute, Inc, Cary, NC). Test-retest reliability was assessed with intraclass correlations. ${ }^{52}$ For depressive symptoms, stepwise linear regression analyses were performed to assess the relationship between ladder responses and depressive symptoms, controlling for age, gender, number of parents in the home, and father's education, and psychological covariates. A baseline model with sociodemographic covariates was run first. Then, ladder rankings were added individually to the baseline model to assess the amount of additional variance that each ladder explained. Next, ladder rankings were added together to the baseline model to determine whether each independently predicted depressive symptoms. This entire process then was repeated with both sociodemographic and psychological covariates in the baseline model to provide a more stringent test of the discriminant validity of the ladders. For overweight and obesity, individual and combined logistic regression analyses controlling for all covariates were performed. Because mental and physical health may be related, these analyses also controlled for depressive symptoms in addition to self-esteem and popularity. Odds ratios and 95\% confidence intervals associated with a 1-point change in the ladders are reported.

Because of the theoretical importance of age in the development of perceptions of social status, a ladder $\times$ age interaction was assessed in all multivariate analyses. To determine whether gender was an important modifying factor, we also tested for ladder $\times$ gender interactions. No significant interactions were found in either linear or logistic regression modeling, so none are reported. Because $22.3 \%$ of families in GUTS had more than 1 child enrolled in the study, multivariate analyses were performed using generalized estimating equations to account for intrafamilial clustering among siblings. ${ }^{53}$ This analytic technique takes into consideration in the regression analyses family effects that result from this clustering

\section{RESULTS}

\section{Description of SSS Among Adolescents}

Mean society ladder rank was $7.2 \pm 1.3$, and mean community ladder rank was $7.6 \pm 1.7$. Responses ranged from 1 to 10 for both ladders. Nonresponse rates among the adolescents were very low for these items: approximately $2 \%$. There were no significant gender differences in perceptions of familial placement in society. However, girls' perceptions of personal placement within the school community were significantly higher than boys' $\left(\mu_{\text {girls }}=7.7 \pm 1.6 \mathrm{vs}\right.$ $\left.\mu_{\text {boys }}=7.5 \pm 1.8 ; P<.001\right)$. The Spearman rank correlation between adolescent and maternal society ladder responses was $0.38(P<.001)$. Although significant, the moderate degree of this correlation suggests that maternal and adolescent perceptions of standing within society differ considerably, which supports the theorized differences between adolescent- and parent-based measures. In addition, the correlation between adolescent and maternal responses to the community ladder was very weak (Spearman's $\rho=0.13 ; P<.01$ ). This may reflect the different language anchoring of this ladder between adolescent and adult versions mentioned above. Looking at within-person correlations between the society and school community ladder responses reveals that the ladders are tapping 2 distinct domains of social status. For adolescents, the Spearman rank correlation between society and community ladders was moderate at $0.35(P<.001)$. The correlation between society and community ladders was stronger for the mothers (Spearman's $\rho=0.61 ; P<.001$ ), suggesting that perceptions of standing in reference to different social environments becomes more similar as individuals mature. The correlation between the adolescent's society ladder ranking and father's education was weak (Spearman's $\rho=0.21 ; P<.01$ ), indicating, as hypothesized, that objective and subjective SES are different components of social status.

\section{Analyses Assessing Potential Developmental Changes in SSS}

As hypothesized, adolescents tended toward higher society ladder rankings compared with their mothers $\left(\mu_{\text {teen }}=7.2 \pm 1.3\right.$ vs $\mu_{\text {mom }}=6.8 \pm 1.2 ; P=$ .002). Correlational analyses also showed that the strength of the correlation between adolescent and maternal society ladder rankings increased with age (Spearman's rho $=0.31$ among those younger than 15 and Spearman's rho $=0.45$ among those 15 years or older). Although striking, this difference was not statistically significant. Younger adolescents did have significantly higher perceptions of familial placement in society than older adolescents $\left(\mu_{\text {teens }}\right.$ $<15$ years $=7.3 \pm 1.3$ vs $\mu_{\text {teens }} \geq 15$ years $=7.2 \pm 1.2 ; P<$ $.001)$. Age was not significantly associated with adolescents' responses to the school community ladder. Last, reliability of both ladders is higher among older adolescents, suggesting that the ability to define and accurately report subjective perceptions of social status stabilizes with increasing age.

\section{Associations of the MacArthur Scale of Subjective Social Status and Indicators of Adolescents' Mental and Physical Health}

The results of regression analyses to assess the associations between SSS and depressive symptoms, controlling for SES and other covariates, revealed that higher SSS was associated with fewer depressive symptoms (Table 2). When sociodemographic characteristics were controlled for, as hypothesized, the school community ladder was more strongly associated with depressive symptoms than the society ladder. The community ladder explained an additional $9.5 \%$ of the variance in depressive symptoms, whereas the society ladder explained an additional $4.4 \%$. In the combined model, both ladders were significantly associated with depressive symptoms and together explained an additional $9.9 \%$ of the variance. The community ladder remained more strongly associated with depressive symptoms than the society ladder in this model.

Although both ladders remained significantly associated with depressive symptoms when controlling for self-esteem and popularity, the strength of the association was reduced greatly (Table 2 ). In the combined model controlling for sociodemographic 
TABLE 2. Regression Analyses: Association of Increasing Subjective Social Status and Lower Depressive Symptoms Among Adolescents in the 1999 Growing Up Today Study

\begin{tabular}{lcccccc}
\hline \multirow{2}{*}{ Parameter } & \multicolumn{2}{c}{ No Adjustment for Self-Esteem and Popularity } & & \multicolumn{2}{c}{ With Adjustment for Self-Esteem and Popularity } \\
\cline { 2 - 3 } & Individual Models $\beta$ & Combined Model $\beta$ & & Individual Models $\beta$ & Combined Model $\beta$ \\
\hline Society ladder & $0.45^{*}$ & $0.57^{*}$ & $0.52^{*}$ & $0.12^{*}$ & $0.08^{*}$ \\
Community ladder & $0.12^{*}$ & $0.10^{*}$ & \\
\hline
\end{tabular}

All models adjust for age, gender, nonwhite race, number of parents in home, and father's education.

${ }^{*} P<.001$.

and psychological covariates, both ladders explained an additional $1.7 \%$ of the variance in depressive symptoms. Self-esteem was the factor most strongly associated with depressive symptoms in the final model $\left(\beta_{\text {self-esteem }}=4.65 ; P<.001\right)$.

Table 3 presents odds ratios and $95 \%$ confidence intervals for ladder rankings and father's education in relation to overweight and obesity when controlling for covariates and depressive symptoms. In individual models, SSS and SES were significantly associated with both overweight and obesity in the expected direction. Higher social status was associated with a decreased likelihood of overweight and obesity. The odds ratios for the society and community ladders were almost identical, indicating that the magnitude of the effect of the ladders was virtually the same with regard to obesity. However, society ladder rankings became nonsignificant in the combined model, whereas the community ladder maintained an independent effect. It is interesting to note that the odds ratio for father's education changed very little in the combined model. Thus, these data do not suggest that the effect of objective SES is mediated through SSS but rather that these domains of social status are independently associated with overweight and obesity.

\section{DISCUSSION}

This article reports on a new, adolescent-specific measure of SSS. The development of this indicator follows the American Academy of Pediatrics recommendation that "pediatric investigators, in collaboration with social scientists, should develop and apply research methodologies that will result in careful definitions of, analysis of interactions among, and ultimately documentation of the effects of these variables (gender, race/ethnicity, and SES) on child health." 1 The purpose of this article was to introduce a method for defining social status more fully by providing a youth-specific measure of SSS. When used in conjunction with traditional measures of SES, this new instrument will allow investigators to broaden their analyses of the effects of social status on adolescent health. Our findings indicate that the MacArthur Scale of Subjective Social Status-Youth Version is a reliable measure of SSS and that both dimensions of SSS-perceptions of familial placement in society and personal placement in the school community-correlate with health indicators independent of the effect of a traditional measure of SES.

Data from the United Kingdom led West ${ }^{54}$ to argue that adolescence represents a time when there is an "equalization" in health among varying SES groups and that health differentials reemerge during adulthood when SES rises in importance in determining one's self-concept. In later adolescence and early adulthood, when experience with society broadens and exposes individuals to the wider social stratification present in society and an individual's self-concept matures, SES differentials in health reemerge, perhaps through physiologic changes or a shift in health-promoting or risk-taking behaviors. Our finding that younger adolescents have higher perceptions of placement within society supports this theory. In addition, we found much stronger correlations between the society ladder and father's education among adolescents 15 years of age or older compared with those younger than 15 years. The difference suggests a developmental evolution in SSS. As adolescents age and mature cognitively, their perceptions of social stratification also may mature. Older adolescents, because of an increased ability to think abstractly, may be better able to define and reliably report perceptions of social stratification. Thus, subjective perceptions of social status among older adolescents will align more closely with parental perceptions of social status. Future research on social inequalities in health should consider assess-

TABLE 3. Logistic Regression Analyses: Association of Subjective Social Status and Obesity Among Adolescents in the 1999 Growing Up Today Study

\begin{tabular}{|c|c|c|c|c|}
\hline \multirow[t]{2}{*}{ Model } & \multicolumn{2}{|c|}{ Overweight } & \multicolumn{2}{|c|}{ Obesity } \\
\hline & Odds Ratio & $95 \% \mathrm{CI}$ & Odds Ratio & $95 \% \mathrm{CI}$ \\
\hline \multicolumn{5}{|l|}{ Individual models } \\
\hline Society ladder & 0.93 & $0.90,0.97$ & 0.89 & $0.83,0.95$ \\
\hline Community ladder & 0.94 & $0.91,0.98$ & 0.91 & $0.87,0.97$ \\
\hline Father's education & 0.85 & $0.81,0.89$ & 0.82 & $0.76,0.89$ \\
\hline \multicolumn{5}{|l|}{ Combined model } \\
\hline Society ladder & 0.97 & $0.93,1.01$ & 0.94 & $0.87,1.01$ \\
\hline Community ladder & 0.95 & $0.92,0.99$ & 0.93 & $0.88,0.99$ \\
\hline Father's education & 0.85 & $0.81,0.89$ & 0.83 & $0.76,0.90$ \\
\hline
\end{tabular}

All models adjust for age, gender, nonwhite race, number of parents in the home, self-esteem, popularity, and depressive symptoms. CI indicates confidence interval. 
ing this developmental shift in design and analytic strategies.

The moderate correlations between the society and school community ladders demonstrated in this study support the hypothesis that SSS has 2 components: 1 linked to perceptions of familial placement within American society and 1 linked to individual placement in the school community. The ability to explore how different societal reference groups affect health is a unique innovation of the MacArthur Scale of Subjective Social Status. We hypothesized that the school community ladder would be particularly important in capturing a key aspect of social stratification among adolescents. In part, this is because it is likely that family SES is less salient for adolescents than placement within society is for adults. In addition, peer norms, perceptions, and behaviors are important determinants of adolescents' health and well-being. These may be reflected in the school community ladder. The school community ladder was strongly associated with both popularity and global self-esteem in these youths. We also found that the school community ladder was more strongly associated with both depressive symptoms and overweight/obesity among adolescents than the society ladder in cross-sectional analyses. When we controlled for self-esteem and popularity, the relationships between school community ladder rankings and health indicators remained significant. This suggests that objective and subjective social status both may have direct and indirect effects on these health outcomes. Further research is needed to understand how subjective perceptions of social status affect health prospectively and the interplay between stratification within the local community and stratification within society at large in the creation of health differentials. In addition, further research will help to elucidate the factors underlying adolescents' perceptions of stratification both in the local community and within society at large.

There are some limitations of these data that must be acknowledged. Although the measure of depressive symptoms in this study was related to SSS, it was not significantly associated with father's education. This measure of depressive symptoms, although adapted from a scale validated for use in adolescent girls, is not standardized and is not validated for use among adolescent boys. ${ }^{48}$ Thus, the lack of association between father's education and depressive symptoms could be due to measurement error. However, this lack of association also could be due to the truncated distribution of father's education in this cohort. GUTS is a study of the children of nurses. By its very design, the sample is primarily white and is skewed to the upper end of the SES gradient. This limits generalizability of the results. The limited variance in father's education also may increase the relative power of subjective status compared with objective indicators, although we did find that father's education was associated with overweight and obesity and that the magnitude of the association was similar to that from a larger, more representative sample of adolescents. ${ }^{12}$ Last, as stated above, these data are cross-sectional and therefore do not establish causality. Because these data are cross-sectional, we could not determine whether low popularity or self-esteem led to lower perceptions of standing or whether low perceptions of standing cause social isolation and poor self-concept. By controlling for these psychological states, the analyses demonstrate a direct effect of SSS. They do not assess whether SSS indirectly creates health inequalities by creating lower self-esteem, more social isolation, increased depressive symptoms, and more obesity. These analyses also do not assess whether depression and obesity cause lower perceptions of social status, a social drift hypothesis. The possibility of reverse causation and social drift is most relevant to the school community ladder among adolescents. Despite this possibility, these analyses did continue to show a direct effect of subjective social status. In addition, it should be noted that among adults, some have suggested a social drift hypothesis with regard to the genesis of the SES gradient in health. ${ }^{55}$ However, studies do not support the social drift hypothesis but do support social causation. ${ }^{56}$

\section{CONCLUSION}

The current research suggests that social stratification as reflected by subjective social status may be an important determinant of adolescents' health independent of traditional measures of SES. In this crosssectional sample of adolescents from primarily nonHispanic white, relatively high-SES families, the MacArthur Scale of Subjective Social Status-Youth Version proved to be a reliable indicator that can be used to assess adolescents' perceptions of social stratification and link these perceptions to health outcomes. Additional research using this instrument can increase understanding of developmental changes in perceptions of social status. In this way, researchers will be able to define more fully and precisely the effects of social status on adolescent health. In addition, researchers will be able to use this instrument to increase understanding of how social status influences risk and resilience during the critical developmental period of adolescence by opening up fresh avenues for exploring socioeconomic differences in health. These include understanding the health consequences of discrepant rankings and linking both objective and subjective components of social status to potential biological mediators of the SES-health gradient.

\section{ACKNOWLEDGMENTS}

This work was supported in part by Grant 99110517 from the William T. Grant Foundation (E.G.); a Trustee Grant from the Board of Trustees, Children's Hospital Medical Center, Cincinnati (E.G.); Grant DK46834 from the National Institutes of Health (G.A.C.); and the John D. and Catherine T. MacArthur Foundation Research Network on Socioeconomic Status and Health (N.E.A.).

\section{REFERENCES}

1. Committee on Pediatric Research. Race/ethnicity, gender, socioeconomic status-research exploring their effects on child health: a subject review. Pediatrics. 2000;105:1349-1351

2. Adler NE, Boyce T, Chesney MA, et al. Socioeconomic status and health: the challenge of the gradient. Am Psychol. 1994;49:15-24

3. Anderson NB, Armstead CA. Toward understanding the association of 
socioeconomic status and health: a new challenge for the biopsychosocial approach. Psychosom Med. 1995;57:213-225

4. Williams DR. Socioeconomic differentials in health: a review and a redirection. Soc Psychol Q. 1990;53:81-99

5. Link BG, Phelan J. Social conditions as fundamental causes of disease. J Health Soc Behav. 1995;(extra issue):80-94

6. Montgomery LE, Kiely JL, Pappas G. The effects of poverty, race, and family structure on US children's health: data from the NHIS, 1978 through 1980 and 1989 through 1991. Am J Public Health. 1996;86: 1401-1405

7. Newacheck P, Starfield B. Poverty and childhood chronic illness. Arch Pediatr Adolesc Med. 1994;148:1143-1149

8. Starfield B. Childhood morbidity: comparisons, clusters, and trends. Pediatrics. 1991;88:519-526

9. Egbuonu L, Starfield B. Child health and social status. Pediatrics. 1982; 69:550-557

10. Infant Mortality Rates. Socioeconomic Factors. Washington, DC: US Government Printing Office, National Center for Health Statistics; 1972

11. Wise PH, Kotelchuck M, Wilson ML, Mills M. Racial and socioeconomic disparities in childhood mortality in Boston. N Engl J Med. 1982;313: 360-366

12. Goodman E. The role of socioeconomic status gradients in explaining differences in US adolescents' health. Am J Public Health. 1999;89: $1522-1528$

13. Goodman E, Amick BC, Rezendes MO, Tarlov AR, Rogers WH, Kagan J. Influences of gender and social class on adolescents' perceptions of health. Arch Pediatr Adolesc Med. 1997;151:899-904

14. Lowry R, Kann L, Collins JL, Kolbe LJ. The effect of socioeconomic status on chronic disease behaviors among US adolescents. JAMA. 1996;276:792-797

15. West P, Macintyre S, Annadale E, Hunt K. Social class and health in youth: findings from the West of Scotland Twenty-07 Study. Soc Sci Med. 1990;30:665-673

16. West P. Health inequalities in the early years: is there equalisation in youth? Soc Sci Med. 1997;44:833-858

17. Taylor SE, Kemeny ME, Reed GM, Bower JE, Gruenewald TL. Psychological resources, positive illusions, and health. Am Psychol. 2000;55: 99-109

18. Adler NE, Epel ES, Castellazzo G, Ickovics JR. Relationship of subjective and objective social status with psychological and physiological functioning: preliminary data in healthy white women. Health Psychol. 2000;19:586-592

19. Wilkinson RG. Unhealthy Societies: The Afflictions of Inequality. London, England: Routledge; 1996

20. Wilkinson RG. Health, hierarchy, and social anxiety. Ann N Y Acad Sci. 1999;896:48-63

21. Lynch JW, Smith GD, Kaplan GA, House JS. Income inequality and mortality: importance to health of individual income, psychosocial environment, or material conditions. BMJ. 2000;320:1200-1204

22. Centers R. The Psychology of Social Classes: A Study of Class Consciousness. Princeton, NJ: Princeton University Press; 1949

23. Vanneman R, Pampel F. The American perception of social class and status. Am Sociol Rev. 1968;42:422-437

24. Hodge R, Treiman D. Class identification in the United States. Am J Sociol. 1968;93:535-547

25. Gurin P, Miller A, Gurin G. Stratum identification and consciousness. Soc Psychol Q. 1980;43:30-47

26. Jackman M. The subjective meaning of social class identification in the United States. Public Opin Q. 1979;43:443-462

27. Kleugel J, Smith E. Beliefs about stratification. Annu Rev Sociol. 1981;7: $29-56$

28. Simmons R, Rosenberg M. Functions of children's perceptions of the stratification system. Am Sociol Rev. 1971;36:235-249

29. Centers R. Social class identifications of American youth. J Pers. 1950; 18:290-302

30. Goodman E, Amick BC, Rezendes MO, et al. Adolescents' understanding of social class: a comparison of white upper middle class and working class youth. J Adolesc Health. 2000;27:80-83

31. Ostrove JM, Adler NE, Kuppermann M, Washington AE. Objective and subjective assessments of socioeconomic status and their relationship to self-rated health in an ethnically diverse sample of pregnant women. Health Psychol. 2000;19:613-618

32. Cohen S. Social status and susceptibility to respiratory infections. Ann N Y Acad Sci. 1999;896:246-253

33. Glendinning A, Love JG, Hendry LB, Shucksmith J. Adolescence and health inequalities: extensions to Macintyre and West. Soc Sci Med. 1992;35:679-687

34. Glendinning A, Hendry L, Shucksmith J. Lifestyle, health, and social class in adolescence. Soc Sci Med. 1995;41:235-248

35. Birmaher B, Ryan ND, Williamson DE, et al. Childhood and adolescent depression: a review of the past 10 years. Part I. J Am Acad Child Adolesc Psychiatry. 1996;35:1427-1439

36. Must A, Spadano J, Coakley EH, Field AE, Colditz G, Heitz WH. The disease burden associated with overweight and obesity. JAMA. 1999, 282:1523-1529

37. Gortmaker SL, Must A, Perrien JM, Sobol AM, Dietz W. Social and economic consequences of overweight in adolescence and young adulthood. N Engl J Med. 1993;329:1008-1012

38. Sargent JD, Blanchflower DG. Obesity and stature in adolescence and earnings in young adulthood. Arch Pediatr Adolesc Med. 1994;148: 681-687

39. Flegal KM, Carroll MD, Kuczmarski RJ, Johnson CL. Overweight and obesity in the United States: prevalence and trends, 1960-1994. Int J Obes Relat Metab Disord. 1998;22:39-47

40. Anonymous. Update: prevalence of overweight among children, adolescents, and adults-United States, 1988-1994. MMWR Morb Mortal Wkly Rep. 1997;46:198-202

41. Troiano RP, Flegal KM. Overweight children and adolescents: description, epidemiology, and demographics. Pediatrics. 1998;101:497-505

42. Schonfeld-Warden N, Warden CH. Pediatric obesity. An overview of etiology and treatment. Pediatr Clin North Am. 1997;44:339-361

43. Mokdad AH, Serdula MK, Dietz WH, Bowman BA, Marks JS, Koplan JP. The spread of the obesity epidemic in the United States, 1991-1998. JAMA. 1999;282:1519-1522

44. NCHS. Prevalence of Overweight and Obesity Among Adults in the United States. Hyattsville, MD: Public Health Service; 1999

45. Morrison JA, James FW, Sprecher DL, Khoury PR, Daniels SR. Sex and race differences in cardiovascular disease risk factor changes in schoolchildren, 1975-1990: the Princeton School Study. Am J Public Health. 1999;89:1708-1714

46. Solomon CG, Willett WC, Carey VJ, et al. A prospective study of pregravid determinants of gestational diabetes mellitus. JAMA. 1997; 278:1078-1083

47. Frazier AL, Fisher L, Camargo CA, Tomeo C, Colditz G. Association of adolescent cigar use with other high-risk behaviors. Pediatrics. 2000 106(2). URL: http://www.pediatrics.org/cgi/content/full/106/2/e26

48. Shisslak CM, Renger R, Sharpe T, et al. Development and evaluation of the McKnight Risk Factor Survey for assessing potential risk and protective factors for disordered eating in preadolescent and adolescent girls. Int J Eat Disord. 1999;25:195-214

49. Goodman E, Hinden BR, Khandelwal S. Accuracy of teen and parental reports of obesity and body mass index. Pediatrics. 2000;106:52-58

50. Must A, Dallal GE, Dietz WH. Reference data for obesity: 85th and 95th percentiles of body mass index $\left(\mathrm{ht} / \mathrm{m}^{2}\right)$ and triceps skinfold thickness. Am J Clin Nutr. 1991;53:836-846 (published erratum appears in Am J Clin Nutr. 1991;1954:1773)

51. Harter S. Manual for Self-Perception for Children. Denver, CO: University of Denver; 1985

52. Winer BJ, Brown DR, Michels KM. Statistical Principles in Experimental Design., 3rd ed. New York, NY: McGraw-Hill; 1991

53. Berkey CS, Rockett HR, Field AE, et al. Activity, dietary intake, and weight changes in a longitudinal study of preadolescent and adolescent boys and girls. Pediatrics. 2000;105(4). URL: http:// www.pediatrics.org/cgi/content/full/105/4/e56

54. West P. Inequalities? Social class differentials in health in British youth Soc Sci Med. 1988;27:291-296

55. Macintyre S. The Black Report and beyond: what are the issues? Soc Sci Med. 1997;44:723-745

56. Adler NE, Ostrove JM. Socioeconomic status and health: what we know and what we don't. Ann N Y Acad Sci. 1999;896:3-15 
Adolescents' Perceptions of Social Status: Development and Evaluation of a New Indicator

Elizabeth Goodman, Nancy E. Adler, Ichiro Kawachi, A. Lindsay Frazier, Bin Huang and Graham A. Colditz

Pediatrics 2001;108; 31

DOI: $10.1542 /$ peds.108.2.e31

Updated Information \&

Services

References

Subspecialty Collections

Permissions \& Licensing

Reprints including high resolution figures, can be found at:

http://pediatrics.aappublications.org/content/108/2/e31

This article cites 45 articles, 5 of which you can access for free at: http://pediatrics.aappublications.org/content/108/2/e31\#BIBL

This article, along with others on similar topics, appears in the following collection(s):

\section{Adolescent Health/Medicine}

http://www.aappublications.org/cgi/collection/adolescent_health:med icine_sub

Information about reproducing this article in parts (figures, tables) or in its entirety can be found online at:

http://www.aappublications.org/site/misc/Permissions.xhtml

Information about ordering reprints can be found online: http://www.aappublications.org/site/misc/reprints.xhtml 


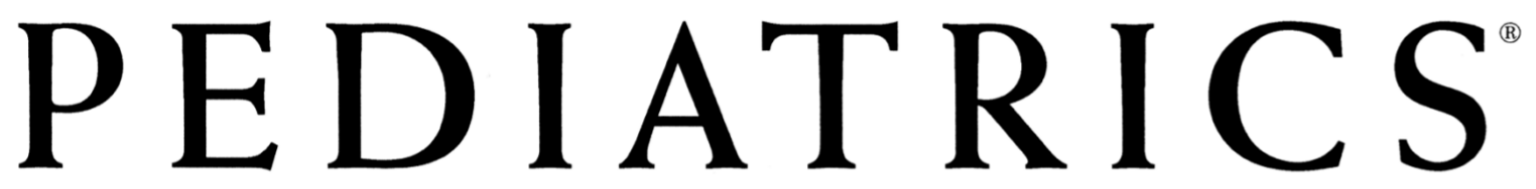

OFFICIAL JOURNAL OF THE AMERICAN ACADEMY OF PEDIATRICS

\author{
Adolescents' Perceptions of Social Status: Development and Evaluation of a New \\ Indicator \\ Elizabeth Goodman, Nancy E. Adler, Ichiro Kawachi, A. Lindsay Frazier, Bin Huang \\ and Graham A. Colditz \\ Pediatrics 2001;108; 31 \\ DOI: $10.1542 /$ peds.108.2.e31
}

The online version of this article, along with updated information and services, is located on the World Wide Web at:

http://pediatrics.aappublications.org/content/108/2/e31

Pediatrics is the official journal of the American Academy of Pediatrics. A monthly publication, it has been published continuously since 1948. Pediatrics is owned, published, and trademarked by the American Academy of Pediatrics, 141 Northwest Point Boulevard, Elk Grove Village, Illinois, 60007. Copyright $\odot 2001$ by the American Academy of Pediatrics. All rights reserved. Print ISSN: 1073-0397.

\title{
American Academy of Pediatrics
}

